\title{
Effect of Helicobacter pylori eradication on gastric metaplasia of the duodenum
}

\author{
S Khulusi, M A Mendall, S Badve, P Patel, C Finlayson, T C Northfield
}

\begin{abstract}
Helicobacter pylori associated duodenal ulcers occur in patches of gastric metaplasia. The pathogenesis of gastric metaplasia is unclear, but it has been produced in experimental animals by acute injury and has been shown to be present to a greater extent of $H$ pylori positive subjects. This study aimed to discover if gastric metaplasia regressed with eradication of $H$ pylori or healing of duodenal ulcers, or both. Thirty two duodenal ulcer patients with $H$ pylori infection confirmed by biopsy urease test and by antral histological examination were studied. Patients were treated with triple therapy (deNol $240 \mathrm{mg}$ twice daily, amoxycillin $500 \mathrm{mg}$ three times daily, and metronidazole $400 \mathrm{mg}$ three times daily) for two weeks after the first endoscopy and were subsequently re-endoscoped. Three duodenal bulb biopsy specimens were obtained per patient at each endoscopy. Biopsy sections were stained with haematoxylin and eosin to determine the severity of duodenitis, and with diastase periodic acid-Schiff/alcian blue to assess the extent of gastric metaplasia. Slides were assessed by two histopathologists unaware of treatment status. $H$ pylori was eradicated in $63 \%$ of subjects and all ulcers were healed at follow up. The median extent of gastric metaplasia at the start of treatment and 6-18 months (median 10) after treatment was compared in the two groups. Gastric metaplasia declined in eradicators from $16 \%$ to $8 \%(p<0.05)$ while in noneradicators there was no significant change ( $25 \%$ initially and at follow up). A positive relation between extent of gastric metaplasia and duodenal inflammation score was present before treatment $\left(r_{\mathrm{s}}=0.74, p<0.001\right)$ and was unchanged after treatment in the non-eradicator group $\left(r_{s}=0.89, p<0.001\right)$. In the eradicator group, however, the inflammation score had significantly declined $(p<0 \cdot 02)$ and the close relation with gastric metaplasia was no longer present. These results suggest that $H$ pylori itself is at least in part responsible for producing gastric metaplasia of the duodenum. (Gut 1995; 36: 193-197)
\end{abstract}

Keywords: Helicobacter pylori, gastric metaplasia, duodenum.

Since the initial identification and isolation of Helicobacter pylori in the early $1980 \mathrm{~s},{ }^{1}$ the importance of this organism in the pathogenesis of duodenal ulceration has become increasingly clear. ${ }^{23} \mathrm{H}$ pylori is found in the antrum of more than $95 \%$ of patients with duodenal ulcer ${ }^{4}$ and eradication reduces the relpase rate in an otherwise frequently relapsing condition. ${ }^{5-7}$

Gastric metaplasia of the duodenum, defined as the presence of groups of gastric mucosal cells within normal duodenal epithelium, is an almost constant feature of duodenal ulcer. ${ }^{89}$ It is also present at the margin of intestinal ulcers in inflammatory bowel diseases ${ }^{10}$ and is believed to be a nonspecific response to injury. ${ }^{11}$ Gastric metaplasia is, however, also present in the proximal duodenum of up to two thirds of non-ulcer dyspepsia patients, ${ }^{12} 13$ occurring with equal prevalence in $H$ pylori positive and negative subjects ${ }^{11} 12$ but having a greater extent in those who are positive. ${ }^{11}$ In animal studies, gastric metaplasia induced by mucosal injury is of rapid onset and resolves over a period of a few months, ${ }^{14}$ showing at least in animal models that it is reversible.

$H$ pylori only colonises gastric epithelium. It is not found in areas of intestinal metaplasia in the stomach ${ }^{15}$ and does not colonise normal duodenal mucosa. ${ }^{916}$ Gastric metaplasia is susceptible to colonisation by $H$ pylori however, resulting in chronic active inflammation, which is believed to be important in the pathogenesis of duodenal ulcer. 91116 Both healing of duodenal ulcer and resolution of active duodenitis follow eradication of $H$ pylori. 5717 The effect of eradicating $H$ pylori on the extent of gastric metaplasia has not been determined.

We aimed to discover if $H$ pylor itself may be responsible for the production of gastric metaplasia of the duodenum by observing whether it regresses after eradication of $H$ pylori in duodenal ulcer patients.

\section{Subjects and methods}

\section{SUBJECTS}

Thirty two consecutive subjects with $H$ pylori positive duodenal ulcer undergoing endoscopy for dyspepsia were studied; 24 were male and eight female (median age 48, range 27-79). Patients receiving non-steroidal anti-inflammatory drugs (NSAIDs) or who had taken antibiotics or acid suppression treatment in the previous month or those with previous gastric surgery were excluded. The study was approved by the St George's Hospital ethics committee and informed consent was obtained from all patients. 


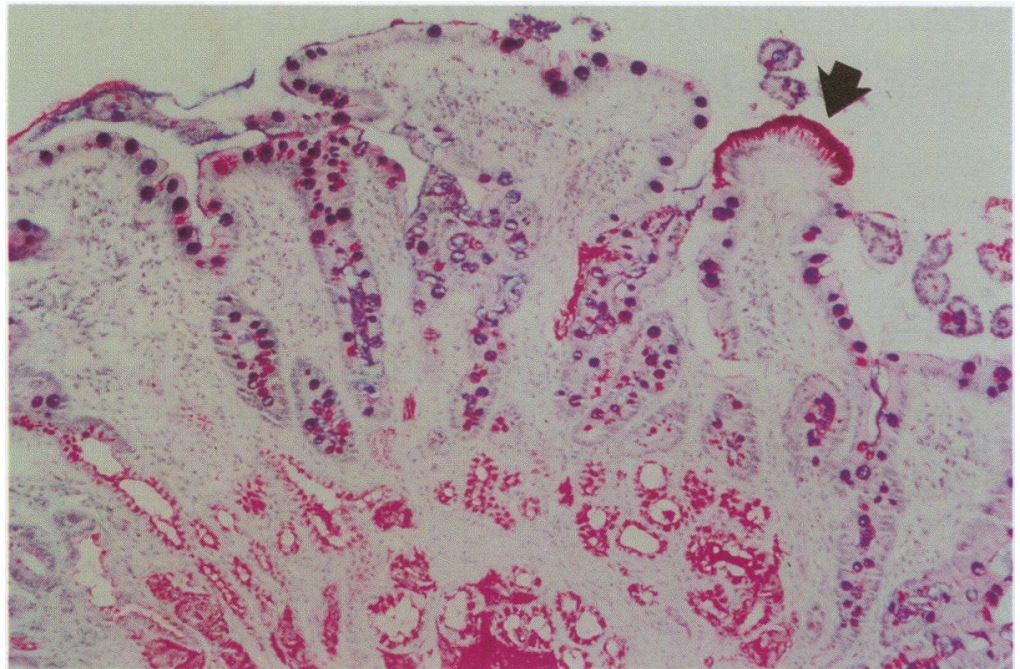

Figure 1: Section of a duodenal biopsy specimen stained with diastase PAS/alcian blue showing an area of gastric metaplasia at the apex of the villus marked with an arrow.

\section{CLINICAL METHODS}

At initial endoscopy, three gastric antral biopsy specimens were obtained $2 \mathrm{~cm}$ from the pylorus, one for rapid urease test and two for histological examination to confirm $H$ pylori infection. Three duodenal bulb biopsy specimens per patient were obtained from the anterior, inferior, and superior walls, at least $1 \mathrm{~cm}$ away from any ulcer margin and from the pylorus. Specimens were placed in buffered formal saline and processed for histological examination.

All patients were treated with antibiotics (amoxycillin $500 \mathrm{mg}$ three times daily and metronidazole $400 \mathrm{mg}$ three times daily) and colloidal bismuth subcitrate (deNol $240 \mathrm{mg}$ twice daily) for two weeks after the first endoscopy and all were re-endoscoped from 6-18 months (median 10) after treatment; antral and duodenal biopsy specimens were repeated from similar topographical sites. Eradication of $H$ pylori was diagnosed by a negative biopsy urease test and negative results on histological examination.

Ten patients required an additional endoscopy less than six months after treatment

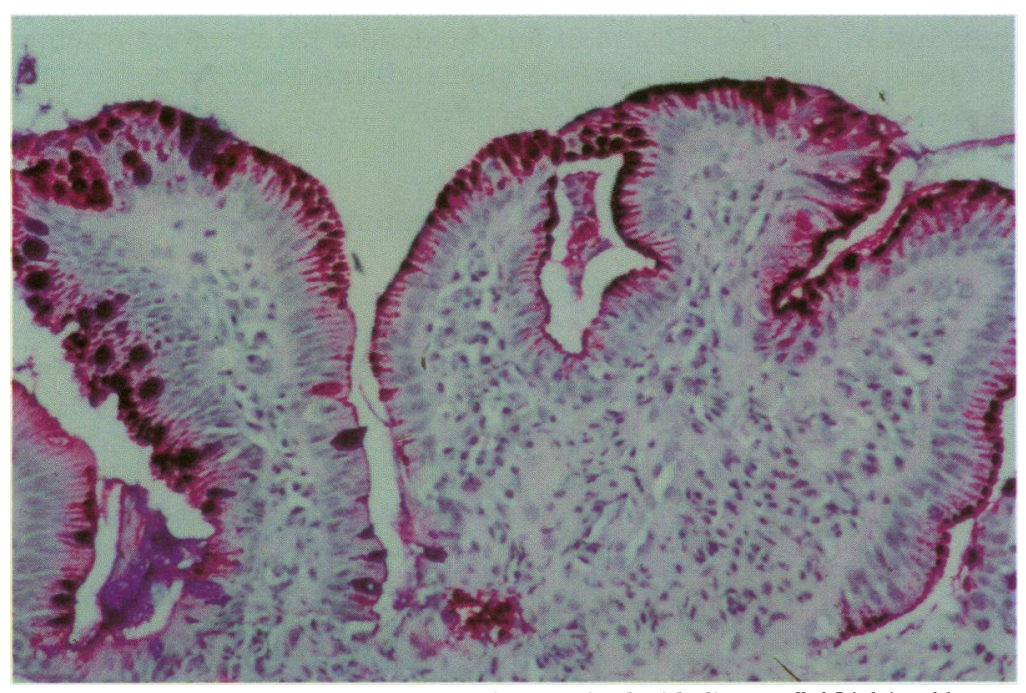

Figure 2: Section of a duodenal biopsy specimen stained with diastase PAS/alcian blue showing extensive gastric metaplasia and inflammatory cell infiltration of the mucosa. because of recurring symptoms. In four no ulcer was detected and antral $H$ pylori was absent on histological testing and on urease test, but in six a persisting ulcer was seen and antral $H$ pylori detected. All six patients were treated with ranitidine $150 \mathrm{mg}$ twice daily for six weeks.

HISTOLOGICAL METHODS

Sections from duodenal biopsy specimens were stained with diastase periodic acid Schiff/alcian blue and examined for gastric metaplasia and duodenitis (Figs 1 and 2), while antral sections were stained with haematoxylin and eosin to detect $H$ pylori. Histological material was examined by two histopathologists unaware of the clinical details. The severity of duodenitis was graded on a scale of $0-3$, corresponding to nil, mild, moderate, and severe mucosal inflammation. ${ }^{18}$ The extent of gastric type epithelium in the duodenal biopsy specimens (gastric metaplasia) was subjectively scored on a scale of 0-10 (representing $0-100 \%$ of the total epithelial surface present ${ }^{19}$ ). For both severity of duodenitis and extent of gastric metaplasia, the mean score of the three specimens obtained from the same subject were used.

\section{STATISTICAL METHODS}

The extent of gastric metaplasia and duodenal inflammation score for the eradicator and noneradicator groups were calculated as medians. Differences between initial and follow up values were compared within groups by the Wilcoxon signed rank test, and between groups by the Mann-Whitney U test. The relation between gastric metaplasia and duodenitis was determined by Spearman's rank correlation coefficient.

\section{Results}

ERADICATION AND ULCER HEALING RATE

$H$ pylori was eradicated in 20 patients and persisted in 12 . There was no significant difference between eradicators and non-eradicators with respect to age, sex, length of follow up, smoking or a family history of peptic ulceration (Table). At the time of re-biopsy no active ulcers were seen, however, in patients who had failed to eradicate $H$ pylori endoscopic evidence of duodenitis was seen in eight of 12 patients and duodenal cap deformities of previous ulceration in six of 12. Ranitidine was required for six patients in the non-eradicator group. There was no significant difference in

Patient characteristics

\begin{tabular}{|c|c|c|}
\hline & $\begin{array}{l}\text { Eradicators } \\
(n=20)\end{array}$ & $\begin{array}{l}\text { Non-eradicators } \\
(n=12)\end{array}$ \\
\hline $\begin{array}{l}\text { Median age (range) } \\
\text { Male/female } \\
\text { Smokers }\end{array}$ & $\begin{array}{l}56(27-78) \\
14 / 6 \\
12\end{array}$ & $\begin{array}{l}48(34-79) \\
10 / 2 \\
5\end{array}$ \\
\hline $\begin{array}{l}\text { ulcer } \\
\text { Length of follow up (month) }\end{array}$ & $\begin{array}{l}11 \\
10(6-18)\end{array}$ & $\begin{array}{l}5 \\
10(6-18)\end{array}$ \\
\hline
\end{tabular}




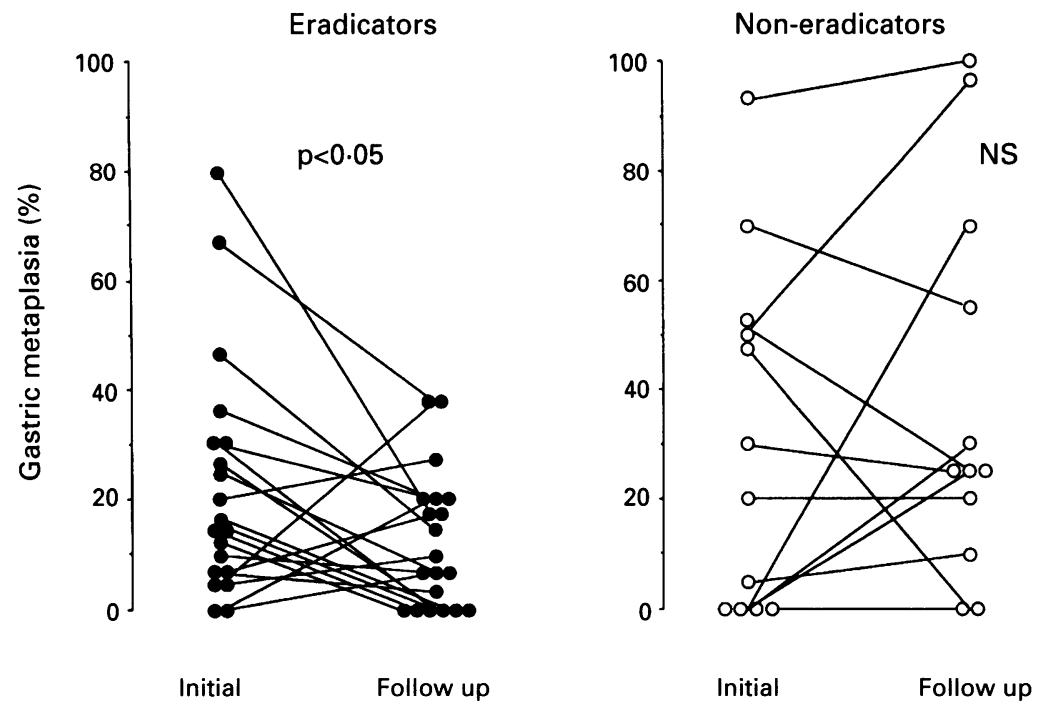

Figure 3: Effect of $\mathrm{H}$ pylori eradication on median gastric metaplasia.

the mean extent of gastric metaplasia between these subjects and non-eradicators not receiving $\mathrm{H}_{2}$ receptor antagonists, showing that this treatment is unlikely to have influenced the results of our non-eradicator group.

\section{EFFECT OF ERADICATION ON GASTRIC}

METAPLASIA

The median extent of gastric metaplasia after eradication of $H$ pylori declined from $16 \%$ (range $0-80$ ) to $8 \%$ (range $0-39$ ) over the period of follow up (Wilcoxon signed rank test $\mathrm{p}<0.05)$ but no significant change was seen in
Eradicators

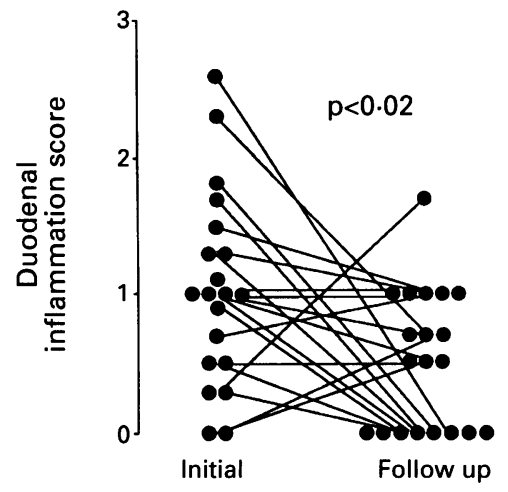

Non-eradicators

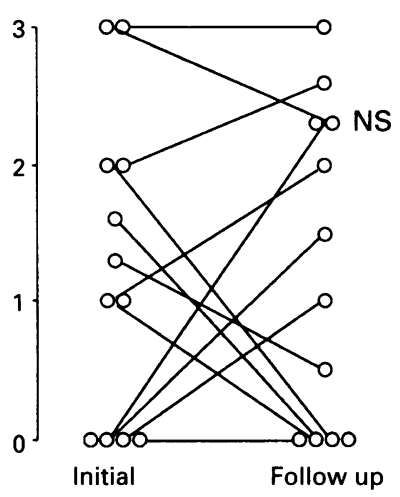

Figure 4: Effect of $\mathrm{H}$ pylori eradication on median duodenal inflammation scores. non-eradicators (25\%, range 0-93; $v 25 \%$, range $0-100$ ) (Fig 3). No significant difference in the extent of gastric metaplasia was found between the two groups initially, however a lower extent of gastric metaplasia was detected in eradicators at follow up (Mann-Whitney U test, $\mathrm{p}<0.02$ ).

\section{RELATION BETWEEN GASTRIC METAPLASIA AND} DUODENITIS

Figure 4 shows the duodenal inflammation scores initially and at follow up in the eradicator and non-eradicator groups. There was a significant reduction in duodenal inflammation after $H$ pylori eradication (Wilcoxon signed rank test, $\mathrm{p}<0.02$ ).

Figure 5 shows the relation between duodenal inflammation score and the extent of gastric metaplasia. A positive relation was present before treatment $\left(r_{\mathrm{s}}=0.74, \mathrm{p}<0.001\right)$ (Fig 5A) and at follow up in the non-eradicator group $\left(r_{\mathrm{s}}=0.89 \mathrm{p}<0.01\right)$ (Fig 5B). In the eradicator group, however, the same close relation between duodenal inflammation and gastric metaplasia was no longer present at follow up (Fig 5C).

\section{Discussion}

This study shows that the extent of gastric metaplasia in the duodenum is reduced after $H$ pylori eradication but not after duodenal ulcer healing alone. This suggests that $H$ pylori infection may increase the extent of pre-existing gastric metaplasia. Other studies that have investigated whether non-acid suppressant treatment reverses gastric metaplasia have given conflicting results. Moshal et $a l^{20}$ showed that duodenal ulcer healing after six weeks of colloidal bismuth was associated with reversal of gastric metaplasia while duodenal ulcer healing with $\mathrm{H}_{2}$ receptor antagonist was not. This difference could be explained by an inhibitory effect of bismuth on $H$ pylori although $H$ pylori status after treatment was not reported. A recent study by Noach et $a l^{21}$ of a similar size to this study, showed a trend towards reduction in gastric metaplasia after $H$ pylori eradication. The reduction did not achieve statistical significance, and the authors concluded that $H$ pylori eradication had no effect on gastric metaplasia, although their
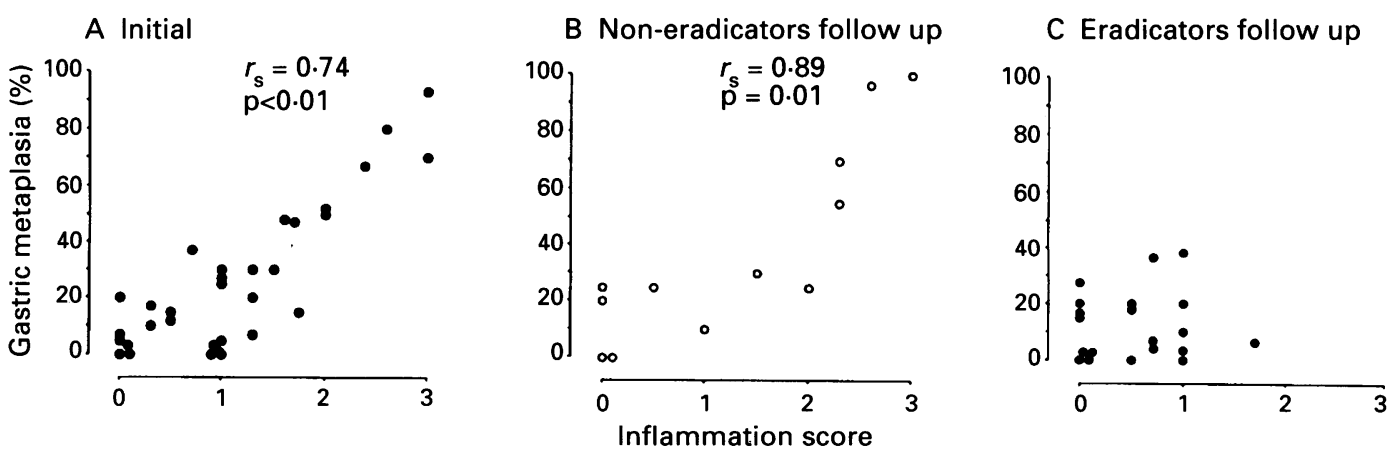

Figure 5: There was a significant relation between gastric metaplasia and duodenal inflammation score in $\mathrm{H}$ pylori infected subjects. 
negative result may be caused by insufficient statistical power.

A study of a highly variable feature such as gastric metaplasia can be associated with sampling error. Biopsy of an inflamed part of the duodenal bulb may result in increased detection of gastric metaplasia compared with an adjacent less inflamed area. ${ }^{12}$ To reduce bias in this study, the endoscopist was unaware of the eradication status of the patients and biopsies were targeted to similar topographical sites. Gastric metaplasia has a patchy distribution in the duodenal bulb and a single anterior duodenal biopsy has been shown to detect $63 \%$ of the gastric metaplasia detected by multiple biopsies. ${ }^{11}$ Three duodenal bulb biopsy specimens, including one from the anterior wall, were used in this study to provide adequate sampling of the extent of gastric metaplasia. A longer period of follow up in our study, might have shown more complete resolution of gastric metaplasia. Animal studies suggest, however, that 10 months of follow up would be expected to be adequate to show maximum resolution. ${ }^{1422}$

In humans even in the absence of duodenal ulceration, the extent of gastric metaplasia is related to gastric acid output ${ }^{11}$ suggesting that acid itself could lead to the formation of gastric metaplasia. It is possible that gastric metaplasia affords some protection against an acidic, gastric environment within the duodenal cap. This is supported by the finding that the incidence of gastric metaplasia is rare beyond the first part of the duodenum. ${ }^{11}$ Other factors such as cigarette smoking, NSAIDs, and male sex are not related to the extent of gastric metaplasia independently of acid output. ${ }^{11} 12$ Duodenal ulcer patients have significantly raised gastric acid production as well as more extensive gastric metaplasia compared with subjects without duodenal ulcer. ${ }^{23} 24$ Studies have attempted to assess the effect of decreasing acid production on gastric metaplasia with conflicting results. Wyatt et $a l^{25}$ showed that two years after vagotomy, patients had a lesser extent of gastric metaplasia than a control group about to undergo vagotomy. In contrast, Jönsson et $a l^{26}$ found no reversal of gastric metaplasia two to three years after parietal cell vagotomy. The same study failed to show any effect after the same period of treatment with cimetidine. Similarly, Noach et $a l^{21}$ found no significant difference in the mean extent of gastric metaplasia between patients taking $\mathrm{H}_{2}$ receptor antagonists for more than a year and subjects not taking these drugs. In our study ranitidine was used in six non-eradicators with persisting duodenal ulcer. No significant difference in the extent of gastric metaplasia was detected between these subjects and noneradicators who had not received ranitidine. It is possible that the degree of acid suppression produced by $\mathrm{H}_{2}$ antagonists, at the doses given in these studies, was insufficient to affect gastric metaplasia.

Our results confirm that a basal level of gastric metaplasia is present, which is independent of $H$ pylori; this is consistent with previous reports implicating possible genetic factors ${ }^{13}$ or gastric acid secretion ${ }^{19}$ in the formation of gastric metaplasia. There are two possible mechanisms by which $H$ pylori itself could increase this basal level of gastric metaplasia. Firstly, $H$ pylori infection has been shown to increase gastric acid production in duodenal ulcer patients leading to greater duodenal acidity. ${ }^{27}$ The second possibility is that infection of gastric metaplasia with $H$ pylori leads to duodenal inflammation, provoking extension of gastric type epithelium as a response to injury. Results from our study support this possibility, as they show a close association between severity of duodenal inflammation and extent of gastric metaplasia, and reduction in both after $H$ pylori eradication. Recent studies, including our own, ${ }^{28} 29$ have shown that infection density is greater in the antrum of $H$ pylori positive patients who have duodenal ulcer than those who do not. It is therefore possible that subjects with a sufficiently high infection density in the gastric antrum are more likely to develop colonisation of gastric metaplasia of the duodenum, which in turn leads to duodenal inflammation generating more extensive gastric metaplasia. This could result in greater colonisation and more severe inflammation of the duodenum, eventually leading to ulceration.

This study has been presented to the British Society of Gastroenterology, September 1993 and has been published in abstract form in Gut 1993; 34 (suppl 4): S50.

SK was supported by the Astra Foundation Research Fellowship for Gastroenterology.

1 Marshall BJ, Warren JR. Unidentified curved bacilli in the stomach of patients with gastritis and peptic ulceration. Lancet 1984 i: 1311-5.

2 Graham DY. Campylobacter pylori and peptic ulcer disease. Gastroenterology 1989; 96: 615-25.

3 Tytgat GN, Noach L, Rauws EA. Helicobacter pylori. Scand $\mathcal{f}$ Gastroenterol Suppl 1991; 187: 1-8.

4 Blaser MJ. Helicobacter pylori and the pathogenesis of gastroduodenal inflammation. F Infect Dis 1990; 161 626-33.

5 Marshall BJ, Goodwin CS, Warren JR, Murray R, Blincow ED, Blackbourn SJ, et al. Prospective double-blind trial of duodenal ulcer relapse after eradication of Campylobacter pylori. Lancet 1988; ii: 1439-42.

6 Graham DY, Lew GM, Klein PD, Evans DG, Evans DJ Saeed ZA, et al. Effect of treatment of Helicobacter pylor infection on the long-term recurrence of gastric or duodenal ulcer. A randomised, controlled study. Ann Intern Med 1992; 116: 705-8.

7 Rauws EA, Tytgat GN. Cure of duodenal ulcer associated with eradication of Helicobacter pylori. Lancet 1990; 335: with eradic

8 Caselli M, Trevisani L, Aleotti A, Bovolenta MR, Stabellini G. Gastric metaplasia in duodenal bulb and Campylobacter-like organisms in development of duodenal ulcer. Dig Dis Sci 1989; 34: 1374-8.

9 Carrick J, Lee A, Hazell S, Ralston M, Daskalopoulos G. Campylobacter pylori, duodenal ulcer, and gastric metaplasia: possible role of functional heterotopic tissue in ulcerogenesis. Gut 1989; 30: 790-7.

10 Wright NA, Pike C, Elia G. Induction of a novel epidermal growth factor-secreting cell lineage by mucosal ulceration in human gastrointestinal stem cells. Nature $1990 ; 343$ 82-5.

11 Wyatt JI, Rathbone BJ, Sobala GM, Shallcross T, Heatley RV, Axon AT, et al. Gastric epithelium in the duodenum: RV, Axon AT, et al. Gastric epithelium in the duodenum: its association with Helicobacte

12 Frierson HJ, Caldwell SH, Marshall BJ. Duodenal bulb biopsy findings for patients with non-ulcer dyspepsia with or without Campylobacter pylori gastritis. Mod Pathol 1990; 3: 271-6.

13 Kreuning J, Wal AM, Kuiper G, Lindeman J. Chronic nonspecific duodenitis. A multiple biopsy study of the duodenal bulb in health and disease. Scand $\mathcal{f}$ Gastroentero Suppl 1989; 167: 16-20.

14 Tatsuta M, Iishi H, Yamamura H, Yamamoto R, Taniguch $H$. Enhancement by tetragastrin of experimental induction of gastric epithelium in the duodenum. Gut 1989; 30: 311-5.

15 Fiocca R, Villani L, Turpini F, Turpini R, Solcia E. High incidence of Campylobacter-like organisms in endoscopic 
biopsies from patients with gastritis with or without peptic ulcer. Digestion 1987; 38: 234-44

16 Johan G, Offerhaus A, Molyvas EN, Hoedemaeker PJ. Helicobacter pylori infection of gastric mucin cell metaplasia: the duodenum revisited. If Pathol 1990; 162: 239-43.

17 Bayerdorffer E, Ottenjann R. The role of antibiotics in Campylobacter pylori associated peptic ulcer disease. Scand F Gastroenterol Suppl 1988; 23: 93-100.

18 Fitzgibbons PL, Dooley CP, Cohen H, Appleman MD. Prevalence of gastric metaplasia, inflammation, and Campylobacter pylori in the duodenum of members of a normal population. Am 7 Clin Pathol 1988; 90: 711-4.

19 Wyatt JI, Rathbone BJ, Dixon MF, Heatley RV. Campylobacter pyloridis and acid induced gastric metaplasia in the pathogenesis of duodenitis. I Clin Pathol 1987; 40: 841-8.

20 Moshal MG, Gregory MA, Pillay C, Spitaels JM. Does the duodenal cell ever return to normal? A comparison between treatment with cimetidine and deNol. Scand $\mathcal{F}$ Gastroenterol Suppl 1978; 13: 51-8.

21 Noach LA, Rolf TM, Bosma NB, Schwartz MP, Oosting J, Rauws EAJ, et al. Gastric metaplasia and Helicobacter pylori infection. Gut 1993; 34: 1510-4.

22 Florey $H$, Harding $H$. The healing of artificial defects of the duodenal mucosa. F Pathol Bacteriol 1935; 40: 211-8.

23 Marshall BJ, Barrett LJ, Prakash C, McCallum RW, Guerrant RL. Urea protects Helicobacter (Campylo- bacter) pylori from the bactericidal effect of acid. Gastroenterology 1990; 99: 697-702.

24 Graham DY, Opekun A, Lew GM, Evans DJ, Klein PD, Evans DG. Ablation of exaggerated meal-stimulated gastrin release in duodenal ulcer patients after clearance of Helicobacter (Campylobacter) pylori infection. $\mathrm{Am} \mathcal{F}$ Gastroenterol 1990; 85: 394-8.

25 Wyatt JI, Rathbone BJ. Gastric metaplasia in the duodenum and Campylobacter pylori. Gastroenterol Clin Biol 1989; 13: 78-82B.

26 Jönsson KA, Strom M, Bodemar G, Norrby K. Histologic changes in the gastroduodenal mucosa after long-term medical treatment with cimetidine or parietal cell vagomedical treatment with cimetidine or parietal cell vagoGastroenterol 1988; 23: 433-41.

27 Levi S, Beardshall K, Haddad G, Playford R, Ghosh P, Calam J. Campylobacter pylori and duodenal ulcers: the gastrin link. Lancet 1989; i: 1167-8.

28 Khulusi S, Mendall MA, Patel P, Levy J, Goggin PM, Northfield TC. Quantitative study of $\mathrm{H}$ pylori infection density, urease activity and pathogenicity [Abstract]. Gut 1993; 34: (suppl 4) S50.

29 Eidt S, Stolte M. Differences between helicobacter associated gastritis in patients with duodenal ulcer, pyloric ulcer, other gastric ulcers and gastritis without ulcer. In:
Malfertheiner P, Ditschuneit H, eds. Helicobacter pylori Mastritis and peptic ulcer. Berlin: Springer-Verlag, 1990: gastritis 
key topics' category. It should be judged in these terms, of course, as it is not a textbook of paediatric gastroenterology. The authors of the chapters are well recognised names in the community of paediatric gastroenterologists, from North America and from the United Kingdom, with one representative from continental Europe. Predictably, all have undertaken their task competently and successfully.

The success of the publication must depend on the choice of topics included. This is good in the main, but at times somewhat specialist. The generalist who sees children with gastrointestinal problems will find the chapters on oral rehydration solution, constipation, food allergy, inflammatory bowe disease, gastro-oesophageal reflux, recurrent abdominal pain, and gastrointestinal bleeding, of great interest and educational value. The chapter on 'when to transplant the liver in children' fits uncomfortably; it is a very interesting question for the paediatric hepatologist or specialist gastroenterologist but of little relevance to the probable readership of the publication. The chapters on the role of gastrointestinal motility studies and of home parenteral nutrition fall in between, probably The relevance of the book to a reader wil depend on the number of children with these problems they see, and I suspect that the book will be most useful to the general paediatrician and not the general gastroenterologist

In keeping with the ethos of counting credits, I would rate this book as being worth three credits (assuming that most generalists would probably read six chapters, and perhaps spend half an hour on each). By doing this, they are probably learning more than by earning six credits by listening to the same authors giving lectures on the same topics, and in addition they have the book on their shelves afterwards. Paediatricians should put it on their reading list for next term, as should any general gastroenterologist who sees children.

S P DEVANE

\section{NOTES}

\section{Wilson's disease and Menkes' disease}

The 7th International Symposium on Wilson's disease and Menkes' disease will be held in Vienna, Austria on 25-27 August 1995. Further information from: Prof Dr Peter Ferenci, Department of International Medicine IV, Gastroenterology and Hepatology, Währinger Gürtel 18-20, A-1090 Vienna, Austria. Tel: (43 1) 404004741 ; fax: (43 1) 4040047350

\section{Neurogastroenterology}

An International Symposium on Neurogastroenterology will be held on 10-11 November 1995 in Rome, Italy. Further information from: Dr Enrico Corazziari, Cattedra di Gastroenterologia I, Clinica
Medica II, Policlinico Umberto I, V le del Policlinico, 00161, Rome, Italy. Tel/fax: 39 6-4469965

\section{Paediatric gastroenterology}

The 1st International Congress of Pediatric Gastroenterology will be held in Jaipur, India on 12-16 December 1995. Further information from: Dr Balvir S Tomar, Head, Department of Pediatric Gastroenterology, 4 Govind Marg, Jaipur, 302 004, India. Tel: 91141604040 or 605050 ; fax: 91141 563788

\section{Gastroenterology}

A Postgraduate Gastroenterology Course will be held in Oxford on 7-10 January 1996 Further information from: Dr D P Jewell, Gastroenterology Unit, Radcliffe Infirmary, Woodstock Road, Oxford OX2 6HE. Tel: 01865 224829; fax: 01865790792

\section{Inflammatory bowel disease}

The International Inflammatory Bowel Disease Symposium will be held in Chester on 14-16 April 1996. Further information from: Prof Jonathan M Rhodes, Department of Medicine, Liverpool University, L69 3BX. Tel: 0151706 3558; fax: 01517065802.

ABIM announcement regarding change in training requirements for certification in gastroenterology

The American Board of Internal Medicine announces a new policy requiring three years of accredited training in a gastroenterology fellowship programme.

This decision follows a lengthy review by the ABIM Subspecialty Board on Gastroenterology and has the support of the American Gastroenterological Association, the American College of Gastroenterology, the American Society of Gastrointestinal Endoscopy, the American Association for the Study of Liver Diseases, and the Gastroenterology Training Program Directors.

This new policy becomes effective for fellows entering gastroenterology fellowship training programmes in June 1996 and thereafter. Trainees who have questions about this policy should contact the American Board of Internal Medicine, 3624 Market Street, Philadelphia, Pennsylvania, 19104-2675, USA.

\section{Falk Symposia}

Details of Falk Symposia for 1995 and 1996 and the Basel Liver Week 1995 are now available. Further information from: Falk Foundatione V, Leinenweberstraße 5, Postfach 65 29, D-79041 Freiburg, Germany. Fax: 0761/13034-59.

\section{Sir Francis Avery Jones BSG Research Award 1996}

Applications are invited by the Education
Committee of the British Society of Gastroenterology who will recommend to Council the recipient of the 1996 Award. Applications (eighteen copies) should include:

(1) A manuscript (2 A4 pages only) describing the work conducted.

(2) A bibliography of relevant personal publications.

(3) An outline of the proposed content of the lecture, including title.

(4) A written statement confirming that all or a substantial part of the work has been personally conducted in the UK or Eire.

Entrants must be 40 years or less on 31 December 1996 but need not be a member of the BSG. The recipient will be required to deliver a 40 minute lecture at the Spring meeting of the Society in 1996. Applications (eighteen copies) should be made to: The Honorary Secretary, BSG, 3 St Andrews Place, London NW1 4LB by 1 December 1995.

\section{CORRECTIONS}

The authors (Van't Hof et al Gut 1995; 36: 691-5) omitted an acknowledgement from their paper and would like to gratefully acknowledge the support of the Medical Research Council, South Africa.

An authors' error occurred in the paper by Khulusi et al (Gut 1995; 36: 193-7). The second sentence under Clinical Methods should read 'One duodenal biopsy was obtained from the ulcer margin and two from the anterior duodenum', and on the same point the second paragraph of the Discussion should re-affirm that the three duodenal bulb biopsy specimens included 'two from the anterior wall'

Some editorial errors occurred in the paper by Mothes et al (Gut 1995; 36: 548-52). The tenth line of the Methods section should read 'was stopped by the addition of $10 \mathrm{~m}$ acetic acid' and not $100 \mathrm{ml}$. In the legend to Fig 1: lane 2 should read 'gliadin (gli)' and not 'purified gliadin', lane 3 should read 'tryptic digested gliadin (t-gli)' and not 'gliadin'. The abscissa to Fig 3 should begin with zero and not 1 . The legend to Fig 4 should read 'MHC expression by HT-29 cells - influence of gliadin (gli) ( $\bullet$ ), tryptic digested gliadin (t-gli) $(0)$, casein $(\boldsymbol{\nabla})$, tryptic digested casein $(\nabla)$, and $\beta$ lactoglobulin $(\boldsymbol{\square})$ Culture in the presence of interferon $\gamma$ without addition of food derived peptides was $100 \%$. Means of three or four ( $t$-gli, four to seven) individual cultures are shown (^only two cultures performed). For sake of clarity the SEM is given in only one direction'.

Also, 'trypsin' and 'tryptic digestion' has been printed as 'tryptin' and tryptin digestion' throughout the text. 